\title{
Perancangan Database IoT Berbasis Cloud dengan Restful API
}

\author{
Cloud-Based IoT Database Design with Restful API \\ Mohammad Kasyful Anwar ${ }^{1}$, Tjahjanto ${ }^{2}$ \\ 1,2 Magister Komputer, Universitas Budi Luhur, Jakarta, Indonesia \\ E-mail: ${ }^{12011600125 @ ~ s t u d e n t . b u d i l u h u r . a c . i d, ~}{ }^{2}$ cahyanto@budiluhur.ac.id
}

\begin{abstract}
Abstrak
Internet of things (IoT) memiliki potensi besar di era industri 4.0, saat mulai muncul beberapa produk elektronik rumah tangga berbasis IoT seperti lampu, saklar, stop-kontak dan lainnya, dengan IoT perangkat rumah tangga tersebut bisa dikendalikan dan dipantau dari jarak jauh sehingga lebih memudahkan penggunanya. Penyimpanan data IoT berbasis cloud menimbulkan permasalahan keamanan data dan performa throughput pada server. Dalam penelitian ini dibahas mengenai rancangan database berbasis cloud dengan restful API untuk IoT agar data IoT aman dan memiliki throughput yang bagus dengan struktur data yang diatur pada database.
\end{abstract}

Kata kunci: Cloud, IoT, Restful API, Database

\begin{abstract}
The Internet of things (IoT) has great potential in the industrial era 4.0, when several IoT-based household electronic products such as lamps, switches, sockets and others began to appear, with IoT these household devices can be controlled and monitored remotely so that more makes it easy for its users. Cloud-based IoT data storage raises issues of data security and throughput performance on servers. This research discusses the design of a cloud-based database with a restful API for IoT so that IoT data is safe and has good throughput with the data structure that is regulated in the database.
\end{abstract}

Keywords: Cloud, IoT, Restful API, Database

\section{PENDAHULUAN}

IoT merupakan implementasi internet untuk berbagai benda di dunia nyata seperti perangkat elektronik rumah tangga, peralatan industri, transportasi[1], [2] hingga hewan yang diberikan sensor tertanam dan selalu aktif (untuk keperluan penelitian misalnya). Tujuan IoT adalah agar berbagai benda tersebut bisa terhubung dengan internet[3], [4] sehingga memiliki kemampuan untuk dipantau dan dikendalikan dari jarak jauh, data pada perangkat bisa diakses dan dipelajari dari jarak jauh. Berikut adalah beberapa contoh keuntungan IoT :

- Sektor transportasi, dengan IoT trafik lalu lintas kendaraan di jalan bisa dipantau, jika ada kemacetan bisa langsung diketahui dan dilakukan tindakan lebih lanjut seperti rekayasa lalu lintas. Contoh lain, penggunaan bahan bakar kendaraan bisa dipantau sehingga bisa dianalisa lebih lanjut agar penggunaan bahan bakar bisa lebih hemat.

- Sektor rumah tangga, peralatan rumah tangga seperti lampu, kunci, kompor, pakan hewan[5], microwave, kulkas dan lainnya bisa dikendalikan dari jarak jauh bahkan jika pemilik sedang tidak berada di rumah, ini meningkatkan keamanan rumah, selain itu peralatan rumah tangga bisa diketahui data penggunaan listriknya.

- Sektor industri, mesin industri bisa dipantau kinerja dan performa nya, jika terjadi kerusakan bisa terdeteksi dan diberitahukan ke pengguna untuk dilakukan tindakan lebih lanjut seperti perbaikan sebelum kerusakan semakin besar [6]. 
Perangkat IoT memiliki kapasitas penyimpanan yang relative kecil karena harus menyesuaikan ukuran fisik dari perangkat dan biaya jika menggunakan kapasitas penyimpanan yang besar. Penyimpanan IoT juga tidak memiliki backup jika terjadi kerusakan seperti kebakaran atau bencana, jika terjadi seperti itu biasanya perangkat IoT diganti dengan unit baru dan data sebelumnya dibiarkan hilang (karena tidak ada kerugian ekonomis) padahal data tersebut penting untuk dilakukan analisa lebih lanjut untuk pengembangan produk IoT selanjutnya.

Perangkat IoT perlu penyimpanan data berbasis cloud agar data bisa tersimpan dengan aman dengan sistem backup yang handal dan performa throughput yang bagus. Pada penelitian berjudul "IFCIoT: Integrated Fog Cloud IoT Architectural Paradigm for Future Internet of Things" integrasi perangkat IoT dengan cloud membantu meningkatkan performa dan skabilitas dari perangkat IoT [7]. Pada penelitian berjudul "A Cloud-IoT Based Sensing Service for Health Monitoring" perangkat IoT bisa diintegrasikan dengan cloud untuk meningkatkan aksesbilitas dan penggunaan data dari sensor perangkat IoT [8].

Pada penelitian berjudul "IMPLEMENTATION OF FACE SIMILARITY USING TINY FACE DETECTOR" Cloud computing menyediakan komputasi, penyimpanan, layanan dan aplikasi melalui internet [9], dengan cloud computing penyimpanan data bisa diakses dengan internet baik itu membaca data (read) atau menulis data (write) sehingga menjadi solusi penyimpanan IoT karena cukup melalui 1 jalur yang sama yaitu internet. Pada penelitian ini diimplementasikan relational database pada cloud computing agar data tersimpan secara terstruktur sehingga data bisa dikelola dan dianalisa dengan baik.

Relational database merupakan basis data dimana data disimpan dalam bentuk tabel yang terdiri dari baris dan kolom. Relational database memiliki bentuk schema (struktur tabel) yang tetap. Relational database menggunakan index dan key sehingga membuat perintah dalam query dapat dengan cepat melakukan manipulasi data yang terstruktur seperti penelitian yang telah dilakukan berjudul "Perbandingan Performa Relational, Document-Oriented dan Graph Database Pada Struktur Data Directed Acyclic Graph" [10].

Restful API juga diterapkan pada database berbasis cloud pada penelitian ini agar keamanan komunikasi data tetap terjaga dan menghindari peretasan pada database secara langsung. Seluruh perangkat IoT akan berkomunikasi melalui Restful API kemudian data dilanjutkan ke database untuk disimpan. Keamanan database merupakan hal utama dalam penelitian ini karena database berbasis cloud bisa diakses oleh siapa saja di internet seperti penelitian yang berjudul "Penerapan Keamanan Penggunaan Data pada Database Kepegawaian Menggunakan Teknik Transparent Data Encryption (Studi Kasus Sekolah Tinggi Teknologi Payakumbuh)" dan penelitian berjudul "Pengamanan Data pada Media Penyimpanan Cloud Menggunakan Teknik Enkripsi dan Secret Sharing” [11], [12].

REST (Representional State Transfer) adalah suatu arsitektur metode komunikasi yang menggunakan protokol HTTP untuk pertukaran data dengan tujuan untuk menjadikan sistem yang memiliki performa yang baik, cepat dan mudah untuk dikembangkan (scale) terutama dalam pertukaran dan komunikasi data. Terdapat beberapa metode HTTP yang bisa digunakan pada REST yaitu GET, POST, PUT dan DELETE [13].

Sistem web service yang menerapkan prinsip - prinsip REST disebut RESTful. Cara kerja RESTful yaitu client mengirim sebuah permintaan melalui HTTP Request dan server menanggapi permintaan client melalui HTTP Response. Terdapat 2 bagian pesan untuk berkomunikasi dengan server yaitu pesan header dan pesan body. HTTP header merupakan catatan kecil setiap transaksi pada HTTP sedangkan HTTP body yaitu data yang akan dikirimkan [14].

Penelitian mengenai database IoT telah dilakukan sebelumnya dengan judul "Implementasi Teknologi Internet of Things Pada Sistem Pemantauan Kebocoran Gas LPG dan Kebakaran Menggunakan Database Pada Google Firebase" dan "Perbandingan Performa 
Database Apache HBase dan Apache Cassandra Sebagai Media Penyimpanan Data Sensor Internet of Things" [15], [16].

Keterkaitan penelitian ini dengan penelitian-penelitian sebelumnya yaitu pada penelitian sebelumnya, database IoT dirancang menggunakan Google Firebase dan pada penelitian lainnya melakukan perbandingan performa database IoT. Sedangkan pada penelitian ini database IoT dirancang menggunakan relational database dan pengujian keamanan database IoT menggunakan uji coba serangan brute force.

\section{METODE PENELITIAN}

\section{Existing system}

Kondisi saat ini perangkat IoT berjalan masing - masing dengan penyimpanan data sendiri. Data perangkat IoT biasanya dikomunikasikan dengan perangkat pengguna seperti smartphone kemudian data tersebut dikirim ke server cloud, atau dikirimkan langsung ke server cloud. Keamanan data IoT dan database penyimpanannya sangat critical karena server cloud bisa diakses oleh siapa saja di internet [11], [12], struktur data IoT juga harus diatur agar performa throughput menjadi maksimal. Dalam penelitian ini dibahas mengenai bagaimana merancang database untuk IoT yang aman dengan Restful API sebagai firewall atau perantara antara database dengan perangkat IoT dan memiliki throughput yang bagus dengan struktur data yang diatur pada database dan pada saat melakukan komunikasi data dengan Restful API.

\section{Proposed model}

Pada penelitian ini digunakan relational database berbasis cloud dengan 1 domain dan beberapa alamat IP public sebagai backup apabila terkena serangan flooding maka bisa ganti ke IP lainnya serta Restful API sebagai perantara antara database dengan lalu lintas internet agar database tidak terkena peretasan karena database tidak berkomunikasi langsung dengan internet. Restful API juga berfungsi melakukan pengecekan apakah data yang akan dikirim ke database adalah data IoT yang valid sehingga database menjadi lebih aman.

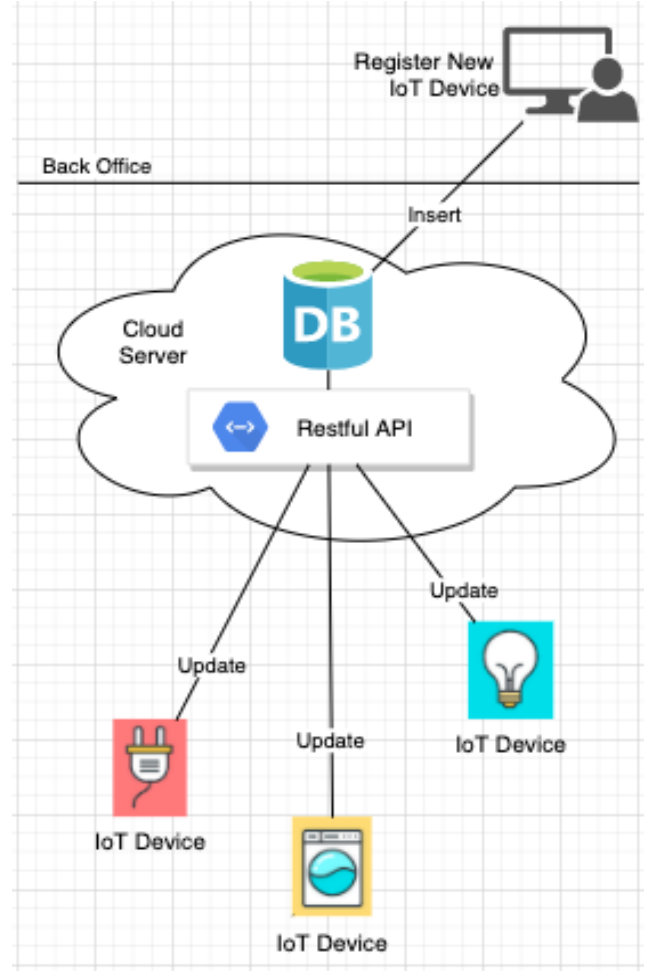

Gambar 1. Proposed model 
Restful API melakukan pengamanan dari sisi pencegahan komunikasi langsung ke database untuk menghindari serangan brute force dan lainnya sehingga memastikan database menjadi lebih aman. Pengamanan yang dilakukan adalah pencegahan database berkemunikasi secara langsung melalui port 3306 dengan menutup port tersebut dan dilakukan uji coba serangan brute force ke database untuk melihat hasil dari pengamanan yang dilakukan.

Berikut adalah flowchart metodologi penelitian yang digunakan dalam perancangan database IoT berbasis cloud dengan Restful API :

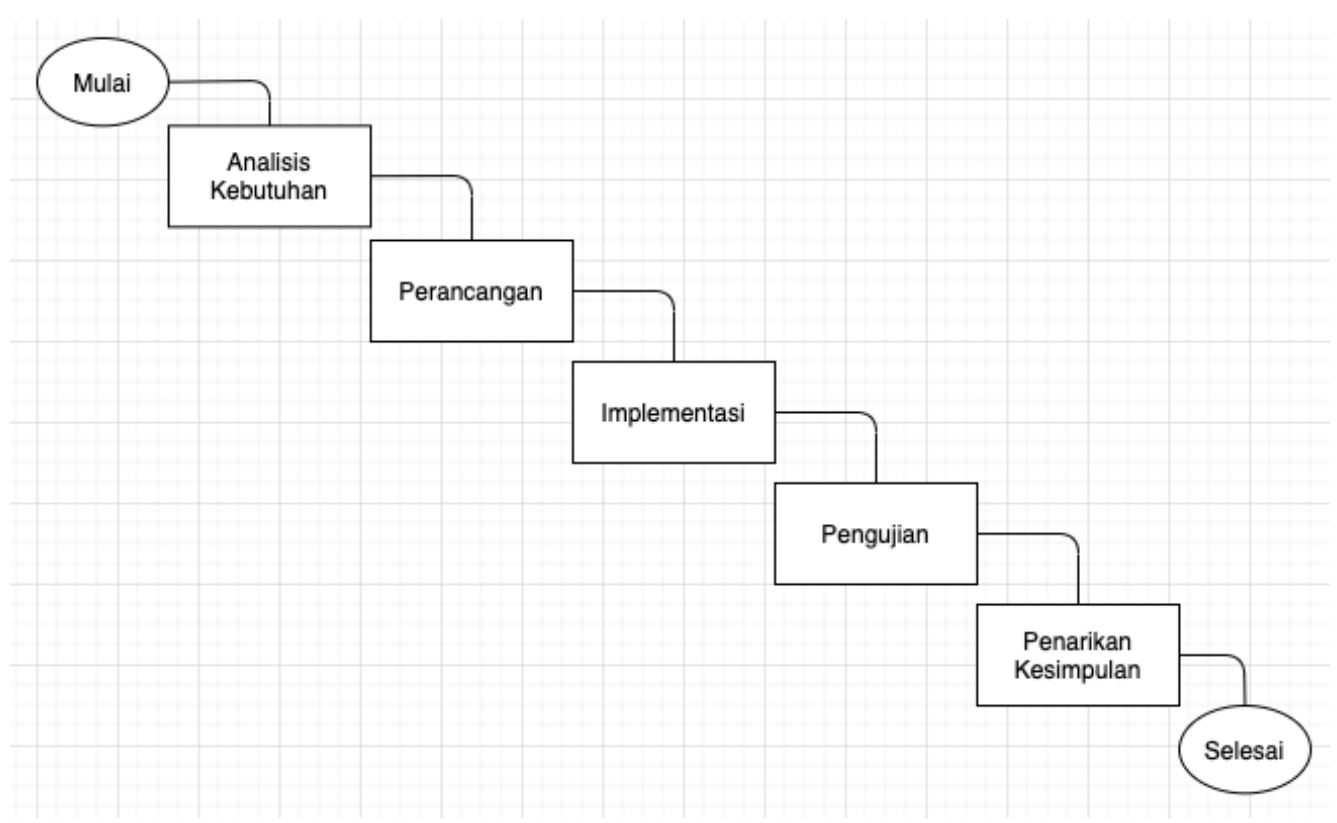

Gambar 2. Metodologi Penelitian

\section{Analisis Kebutuhan}

Menganalisa kebutuhan database dan API untuk penyimpanan data yang aman dan tersedia melalui infrastruktur cloud.

\section{Perancangan}

Perancangan struktur dan desain database beserta API untuk melakukan trasmisi atau update data beserta rancangan pengamanan nya.

\section{Implementasi}

Implementasi database dan API yang telah didesain ke server dengan melakukan coding SQL untuk database dan coding PHP untuk API.

\section{Pengujian}

Melakukan pengujian database dan API yang sudah diimplementasi pada server dengan menggunakan menggunakan metode Black box Testing yaitu pengujian yang didasarkan pada detail aplikasi seperti tampilan aplikasi, fungsi-fungsi yang ada pada aplikasi, dan kesesuaian alur fungsi dengan proses yang diinginkan. [14].

Untuk pengujian fungsional dan fail-over dilakukan simulasi melalui client dengan bantuan aplikasi Postman. Postman adalah aplikasi yang berfungsi sebagai REST Client untuk uji coba REST API. Postman digunakan oleh developer pembuat API sebagai tools untuk menguji API yang telah dibuat. [17] 
Untuk pengujian keamanan dilakukan uji coba serangan brute force ke database IoT dengan menggunakan Hydra di sistem operasi Ubuntu. Hydra adalah salah satu tools security yang dipakai untuk melakukan cracking password secara remote. Tools ini dikembangkan oleh THC (The hacker choice) di bawah lisensi AGPLv3. [18]

\section{Penarikan Kesimpulan}

Penarikan Kesimpulan dilakukan berdasarkan hasil analisa dan pengujian yang telah dilakukan, apakah hasil dari database dan API telah memenuhi kebutuhan dan aman digunakan. Kemanan database menjadi hal utama dalam penelitian ini.

\section{HASIL DAN PEMBAHASAN}

Data yang dianalisa dari IoT adalah data lokasi GPS (Longitude, Latitude), durasi lama hidup perangkat (dalam menit), dan konsumsi listrik. Data pribadi pengguna seperti nama, alamat email, nomor handphone dan lainnya tidak disimpan di database untuk menjaga privasi dari pengguna IoT.

Data lokasi GPS digunakan untuk melihat sebaran perangkat IoT yang ada, ini berguna untuk analisa pemasaran produk IoT tersebut. Data durasi lama hidup perangkat digunakan untuk analisa kualitas dari perangkat IoT apakah setelah dipasarkan dan digunakan oleh customer perangkat tersebut memiliki kualitas yang baik atau tidak. Dan data konsumsi listrik digunakan untuk menganalisa seberapa besar energi yang digunakan oleh perangkat IoT tersebut.

Semua data tersebut digunakan untuk analisa dan kemudian dan dilakukan pengembangan lebih lanjut oleh produsen dari produk IoT tersebut seperti membuat produk baru dengan konsumsi energi yang lebih efisien atau produk baru dengan kualitas yang bagus dan sebagainya.

Data tersebut juga bisa diintegrasikan dengan aplikasi Google Maps untuk melihat sebaran pengguna produk IoT dan menjadi tolak ukur untuk melihat hasil pemasaran di area tertentu dan untuk melakukan pemasaran di area yang belum menggunakan produk IoT.

Data dikirimkan ke server cloud setiap perangkat baru dinyalakan dan cukup 1 kali pengiriman agar lalu lintas data ke server cloud tidak terlalu padat dengan syntax query UPDATE sehingga hanya serial number dari IoT terdaftar saja yang bisa melakukan komunikasi dan menyimpan data ke database. Sebelumnya setiap perangkat IoT dimasukkan ke database (INSERT) setelah selesai proses produksi sehingga produk IoT tersebut terdaftar dan bisa berkomunikasi dengan database. Ini sebagai upaya pengecekan dan validasi agar server cloud dan database tetap tersedia dengan baik dan terhindar dari peretasan. Ini bentuk pengamanan dari sisi database.

Spesifikasi yang digunakan untuk database cloud:

- Server cloud dengan kecepatan internet Up to $1 \mathrm{Gbps}$.

- Server menggunakan sistem operasi Ubuntu 16.04 dengan kapasitas 60 GB

- 1 Domain sebagai alamat yang diakses oleh perangkat IoT untuk melakukan komunikasi data. Domain yang melakukan penggantian IP jika terjadi flooding

- Beberapa alamat IP public untuk server, jika terjadi flooding agar bisa ganti ke IP lainnya.

- Relational Database MySQL.

- Pemrograman server-side PHP dengan framework Codeigniter untuk Restful API sebagai perantara antara database dengan perangkat IoT. 
Berikut adalah desain struktur database IoT :

\begin{tabular}{|c|c|c|c|c|}
\hline Column & Datatype & & PK & $\mathrm{NN}$ \\
\hline lot_SN & INT(11) & $\hat{\imath}$ & $\nabla$ & $\nabla$ \\
\hline$\triangle$ loT_type & CHAR(1) & $\hat{v}$ & $\square$ & $\boldsymbol{\nabla}$ \\
\hline loT_productname & VARCHAR(45) & $\hat{v}$ & $\square$ & $\nabla$ \\
\hline$\Delta$ loT_latitude & $\operatorname{DECIMAL}(9,6)$ & $\hat{v}$ & $\square$ & $\nabla$ \\
\hline$\triangle$ loT_longitude & DECIMAL $(9,6)$ & $\hat{v}$ & $\square$ & $\nabla$ \\
\hline loT_activeminutes & INT(11) & $\hat{\imath}$ & $\square$ & $\boldsymbol{0}$ \\
\hline loT_powerconsumption & INT(11) & $\hat{v}$ & $\square$ & 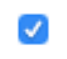 \\
\hline$\diamond$ loT_modifieddate & TIMESTAMP & $\hat{v}$ & $\square$ & $\nabla$ \\
\hline
\end{tabular}

Gambar 3. Struktur Database IoT

Setelah proses produksi perangkat IoT dilakukan pendaftaran perangkat ke database langsung dengan serial number, tipe produk dan nama produknya. Proses pendaftaran perangkat IoT juga bisa melalui aplikasi dengan pengembangan lebih lanjut dari penelitian ini agar pengguna mendapatkan user interface dan user experience yang lebih baik.

Perangkat IoT yang sudah dipasarkan akan berkomunikasi dengan server cloud dengan mengirimkan data setiap perangkat IoT dinyalakan. Data yang dikirimkan berupa update dari lokasi perangkat (Latitude dan Longitude), durasi aktif perangkat dan konsumsi energi dari perangkat. Sehingga data terus diperbarui secara berkala. Data dari luar perangkat IoT atau data yang tidak terdaftar akan diabaikan sehingga lalu lintas data ke server cloud menjadi lancar dan penyimpanan database tidak penuh. Semua hanya data dari perangkat IoT yang terdaftar saja.

Proses update data hanya bisa dilakukan melalui Restful API dan tidak bisa dilakukan melalui database langsung, untuk Restful API menggunakan pemrograman server-side PHP dengan framework Codeigniter [19], PHP adalah bahasa pemrograman server side scripting yang berkomunikasi dengan database. Script PHP akan diproses dan dijalankan oleh server saat ada request dari client. Jenis server yang sering digunakan bersama dengan PHP adalah web server antara lain Apache, Nginx, dan LiteSpeed. [20], [21]

Pada penelitian ini digunakan library Restful API untuk Codeigniter sehingga controller bisa langsung berkomunikasi dengan database tanpa melalui model dan output data langsung berupa JSON (JavaScript Object Notation). [22]

Berikut adalah script PHP Codeigniter dengan menggunakan library Restful API untuk melakukan update data ke database SQL melalui Restful API :

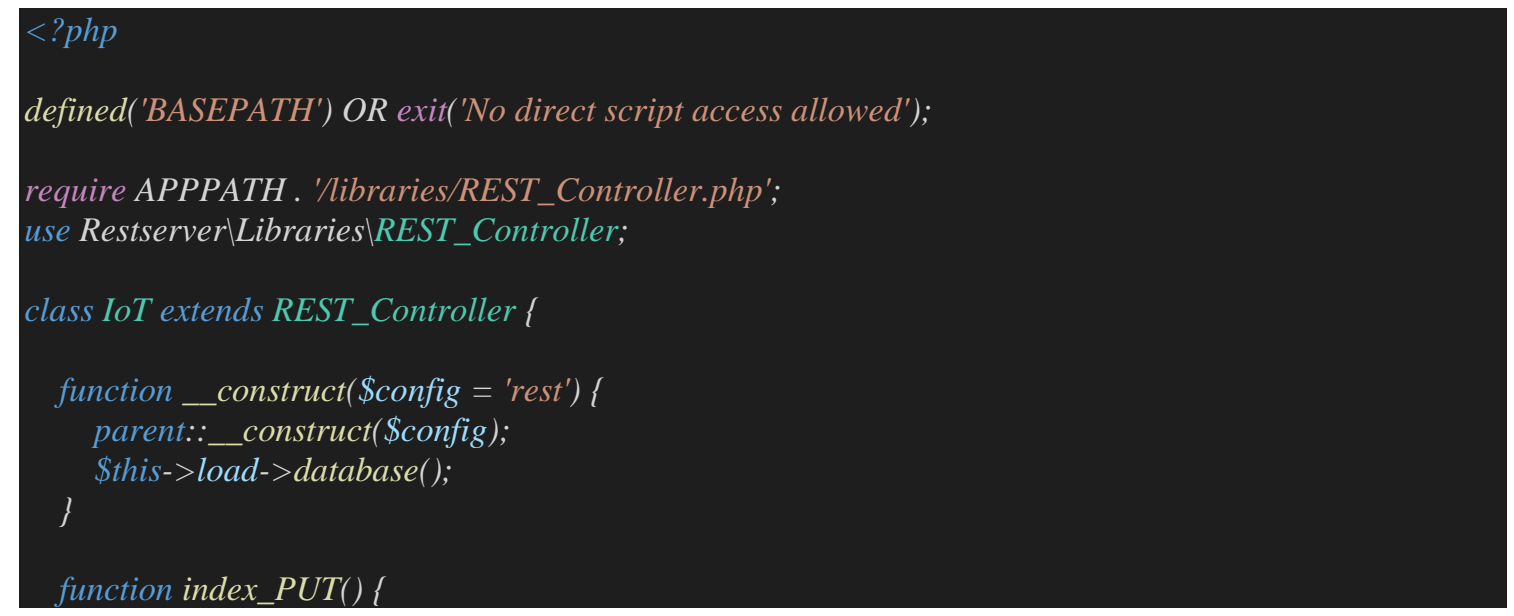




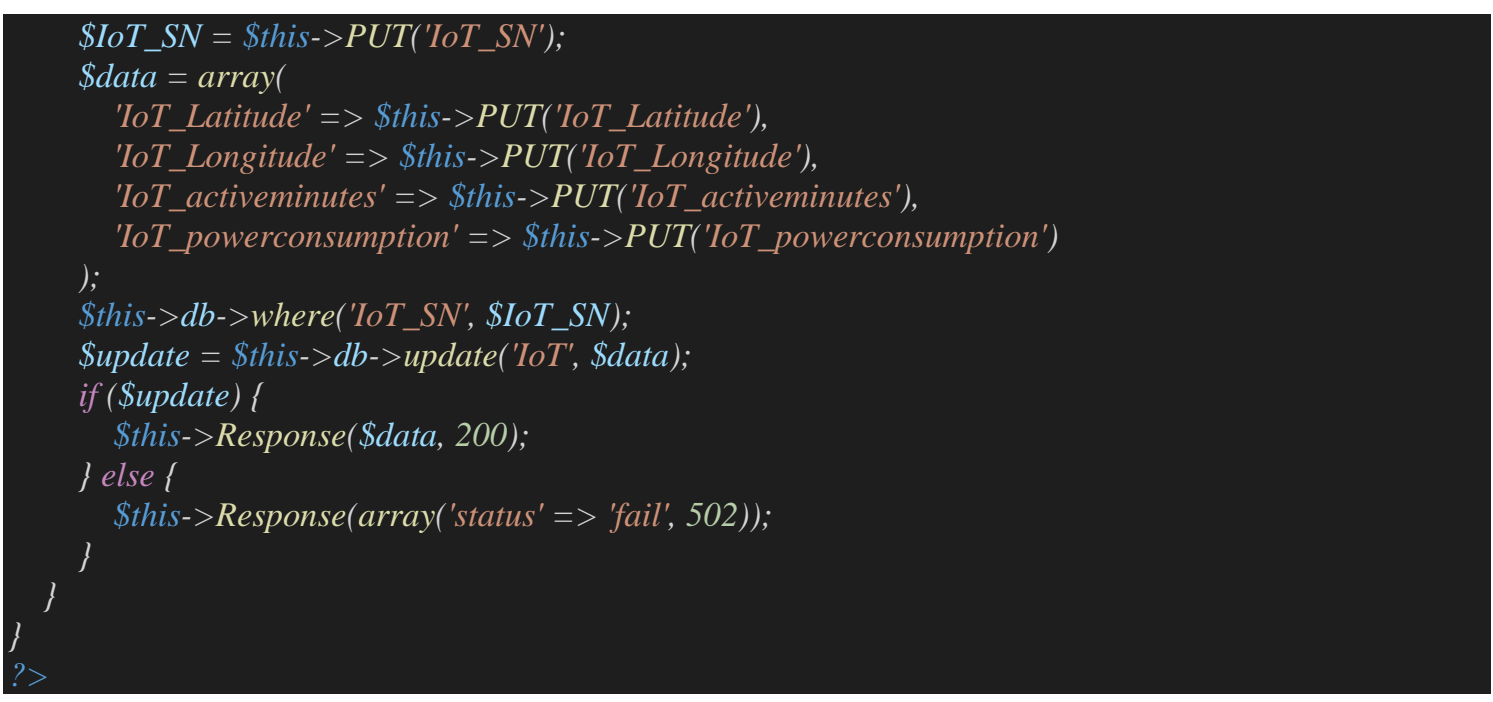

Metode Restful API yang digunakan untuk melakukan update data adalah metode PUT, sedangkan metode lainnya seperti GET, DELETE dan lainnya tidak digunakan karena Restful API hanya digunakan untuk melakukan update data perangkat IoT, tidak untuk membaca data IoT atau menghapusnya agar data tetap aman.

Domain iot.informate.id memiliki beberapa alamat IP sebagai cadangan, apabila terjadi gangguan pada IP utama seperti terkena flooding dan lainnya bisa diarahkan ke IP cadangan agar database IoT tetap bisa diakses.

\section{Pengujian}

Pengujian dilakukan dengan menggunakan metode Black box Testing. Berikut adalah hasil pengujian dengan metode black box pada penelitian ini :

Tabel 1. Hasil Pengujian Black box

\begin{tabular}{|l|l|l|l|}
\hline \multicolumn{1}{|c|}{ Proses } & \multicolumn{1}{|c|}{$\begin{array}{c}\text { Hasil yang } \\
\text { Diharapkan }\end{array}$} & \multicolumn{1}{c|}{ Hasil } & \multicolumn{1}{c|}{ Keterangan } \\
\hline $\begin{array}{l}\text { Input data perangkat IoT } \\
\text { setelah diproduksi } \\
\text { (pendaftaran perangkat IoT) }\end{array}$ & $\begin{array}{l}\text { Berhasil dengan } \\
\text { Status: Query } \\
\text { Completed }\end{array}$ & $\begin{array}{l}\text { Status: 1 row(s) } \\
\text { affected, 0.185 } \\
\text { sec }\end{array}$ & $\begin{array}{l}\text { Valid, proses pendaftaran } \\
\text { perangkat IoT berhasil }\end{array}$ \\
\hline $\begin{array}{l}\text { Update data perangkat IoT } \\
\text { melalui Restful API }\end{array}$ & $\begin{array}{l}\text { Berhasil dengan } \\
\text { Status: 200 OK }\end{array}$ & $\begin{array}{l}\text { Status: 200 OK, } \\
\text { Time: } 94 m s\end{array}$ & $\begin{array}{l}\text { Valid, proses update data } \\
\text { IoT berhasil }\end{array}$ \\
\hline $\begin{array}{l}\text { Fail-over apabila IP utama } \\
\text { tidak bisa diakses } \\
\text { (pergantian IP) }\end{array}$ & $\begin{array}{l}\text { Berhasil dengan } \\
\text { Status: 200 OK }\end{array}$ & $\begin{array}{l}\text { Status: 200 OK, } \\
\text { Time: } \text { 133ms }\end{array}$ & $\begin{array}{l}\text { Valid, proses update data } \\
\text { IoT setalah pergantian IP } \\
\text { berhasil }\end{array}$ \\
\hline $\begin{array}{l}\text { Komunikasi langsung } \\
\text { dengan database melalui } \\
\text { port 3306 }\end{array}$ & Tidak terhubung \\
\hline $\begin{array}{l}\text { Serangan } \text { brute force ke } \\
\text { database }\end{array}$ & Gagal & $\begin{array}{l}\text { Talid, database tidak bisa } \\
\text { diakses secara langsung } \\
\text { hanya bisa melalui API }\end{array}$ \\
\hline
\end{tabular}

Berikut adalah proses pengujian yang dilakukan menggunakan metode black box:

\section{Input data perangkat IoT setelah diproduksi (pendaftaran perangkat IoT)}

Pendaftaran perangkat ke database dengan serial number, tipe produk dan nama produknya, syntax query SQL seperti berikut : 
INSERT INTO 'IoT ('IoT_SN', 'IoT_type', 'IoT_productname`) VALUES ('123456', 'L', 'Smart Lamp');

Maka data produk IoT akan terdaftar seperti berikut :

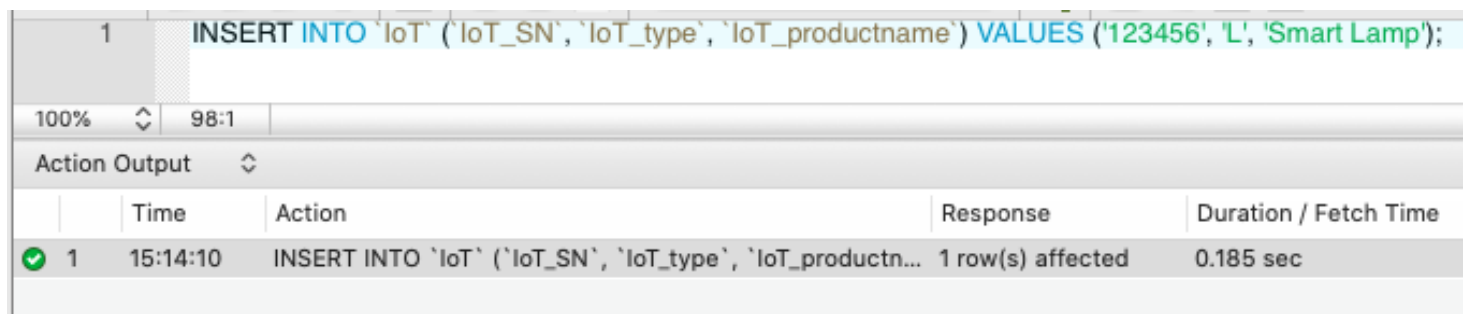

Gambar 4. Pendaftaran Perangkat IoT

\section{Update data perangkat IoT melalui Restful API}

Untuk update data, perangkat IoT mengakses alamat http://iot.informate.id/index.php/IoT dengan mengirim data dengan struktur JSON berikut :

\{

"IoT_SN": "123456",

"IoT_Latitude" : "-6.261009",

"IoT_Longitude" : "106.850973",

"IoT_activeminutes": "1250",

f

"IoT_powerconsumption": "88"

Data pada database akan diperbarui sesuai dengan data yang dikirimkan dengan perantara Restful API. Berikut adalah contoh update data dengan menggunakan aplikasi Postman :

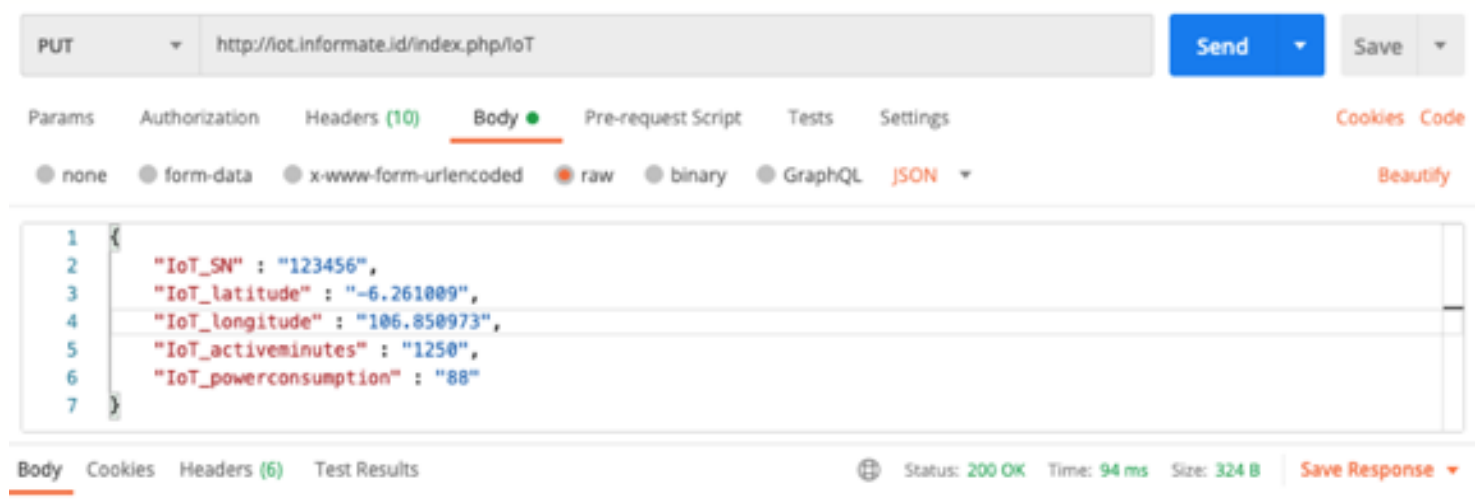

Gambar 5. Update Data IoT 


\section{Fail-over apabila IP utama tidak bisa diakses (pergantian IP)}

Domain iot.informate.id memiliki beberapa alamat IP berikut sebagai cadangan :

\begin{tabular}{l}
$\square \quad$ IP Address Description DNS Name DNS Domain \\
\hline$\square \quad 103.93$. \\
\hline$\quad 103.93$.
\end{tabular}

Displaying 2 item

Gambar 6. Daftar IP Cadangan (disamarkan)

Setelah IP dirubah dilakukan uji coba update data melalui Restful API dengan menggunakan aplikasi Postman seperti berikut :

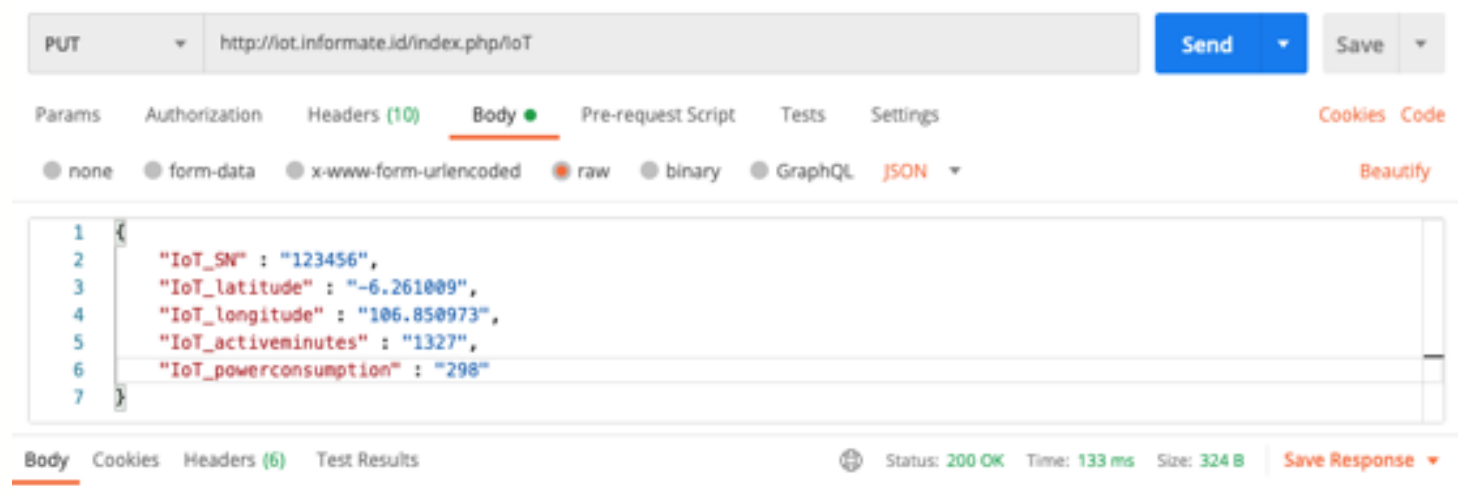

Gambar 7. Update Data IoT setelah Perubahan IP

\section{Komunikasi langsung dengan database melalui port 3306}

Database IoT hanya bisa diakses melalui Restful API dan akses langsung ke database melalui port 3306 (port default MySQL) ditutup agar database aman dari serangan. Ujicoba dilakukan melalui client dengan sistem operasi Ubuntu. Berikut adalah hasil uji coba akses database langsung melalui port 3306 :

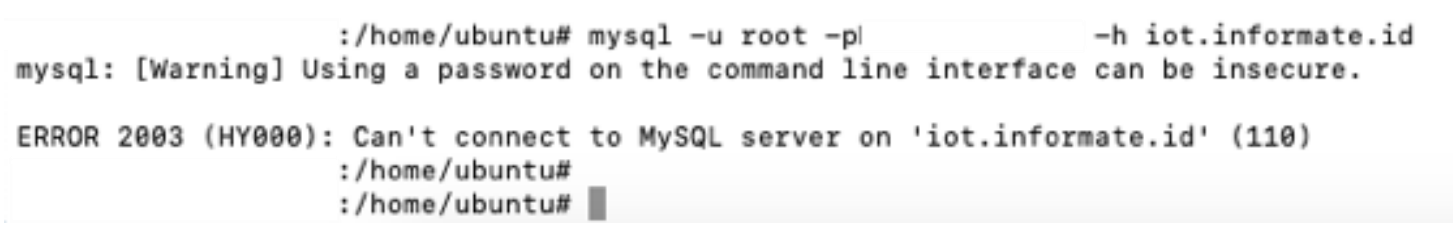

\section{Gambar 8. Uji Coba Akses Database IoT}

\section{Serangan brute force ke database}

Uji coba serangan brute force menggunakan Hydra di sistem operasi Ubuntu. Serangan brute force menggunakan kombinasi 6 username dan 1000 password dengan total 6000 percobaan untuk masuk ke dalam database IoT. Berikut adalah hasil uji coba serangan brute force ke database : 


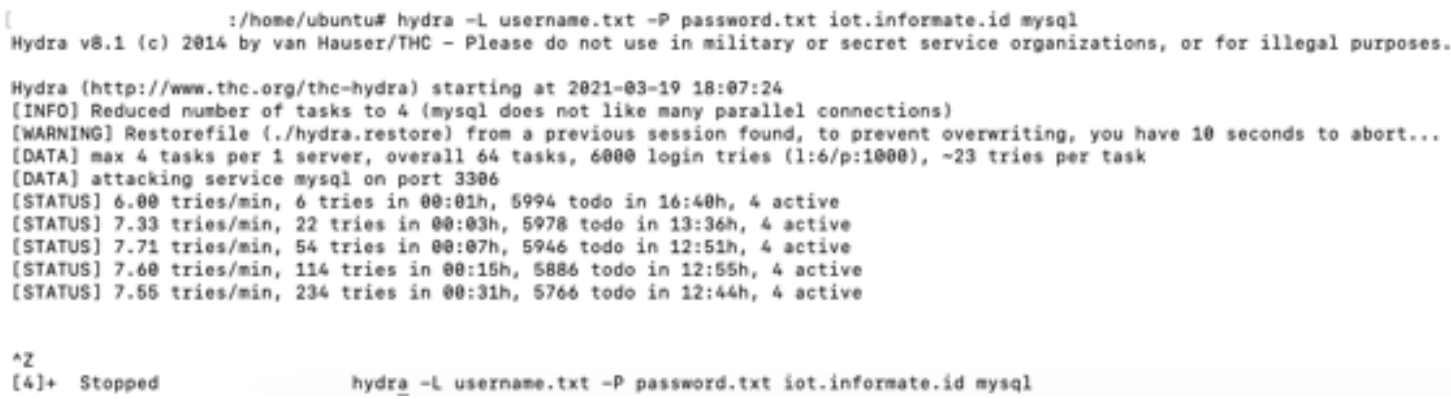

Gambar 9. Serangan Brute force ke Database IoT

Dalam uji coba serangan brute force gagal terhubung ke Database IoT untuk mencoba 6000 kombinasi username dan password untuk memasuki database. Setelah 31 menit uji coba hanya terjadi 234 percobaan dengan 4 koneksi bersamaan dengan kecepatan masing - masing koneksi hanya 7 percobaan per menit dan semua digagalkan oleh database IoT.

Sebagai perbandingan jika serangan brute force berhasil 6000 percobaan bisa dilakukan dalam waktu 1 menit dengan 4 koneksi bersamaan dengan kecepatan masing - masing koneksi 3318 percobaan per menit. Berikut adalah contoh jika serangan brute force berhasil :

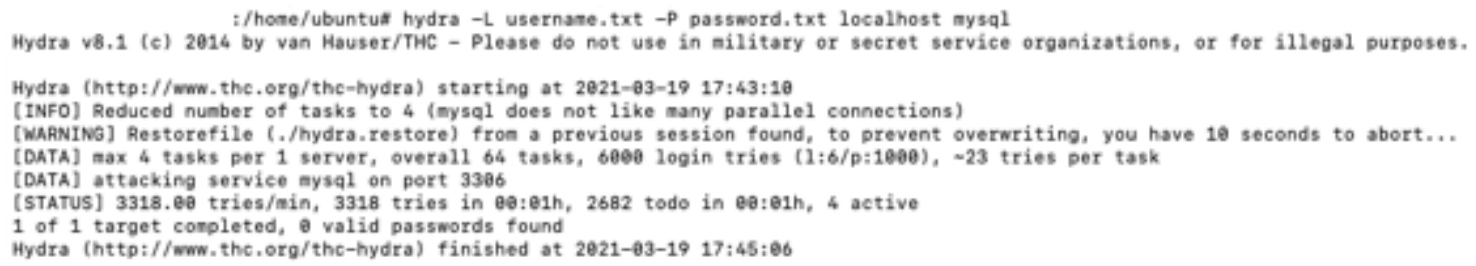

Gambar 10. Contoh Perbandingan Serangan Brute force

\section{KESIMPULAN DAN SARAN}

Dari penelitian yang telah dilakukan, Database IoT berbasis cloud dengan Restful API lebih aman digunakan jika dibandingkan dengan database langsung bisa diakses oleh perangkat IoT atau internet. Peran Restful API sebagai firewall dan akses ke database secara langsung ditutup terbukti membuat database terhindar dari serangan brute force dari uji coba yang dilakukan.

Selanjutnya bisa dilakukan penelitian mengenai pengolahan data IoT yang telah tersimpan tersebut baik dengan metode data mining, atau integrasi dengan aplikasi business intelegence, atau aplikasi sebagai user interface dari data tersebut hingga integrasi dengan Google Maps.

\section{DAFTAR PUSTAKA}

[1] A. Prasetyo and A. R. Yusuf, "Integrated Device Electronic Untuk Sistem Irigasi Tetes Dengan Kendali Internet of Things," J. Ilm. Teknol. Inf. Asia, vol. 14, no. 1, p. 1, 2019, doi: 10.32815/jitika.v14i1.361.

[2] K. Dewi and S. Sulaeman, "Penerapan Teknologi Integrated Device Electronic (Ide) Untuk Peningkatan Produktifitas Hasil Pertanian Pada Purwarupa Kumbung Jamur Tiram Di Dataran Rendah," Semin. Nas. Has. Penelit. (SNP2M PNUP), vol. 0, no. 0, pp. 154159, 2018, [Online]. Available: http://jurnal.poliupg.ac.id/index.php/snp/article/view/784/0.

[3] M. Luckies, G. Azis, E. S. Pramukantoro, and R. A. Siregar, "Pengembangan Internet Gateway Device berbasis Koneksi GPRS untuk Mengoleksi dan Meneruskan Data ke Media Penyimpanan," J. Pengemb. Teknol. Inf. dan Ilmu Komput. Univ. Brawijaya, vol. 
3, no. 1, pp. 40-46, 2019.

[4] E. F. Kurniawan, E. S. Pramukantoro, and F. A. Bakhtiar, "Implementasi Perangkat Internet Gateway Device Untuk Menghubungkan Infrastruktur IoT dan Aplikasi Cloud Menggunakan Narrowband Internet of Things ( NB-IoT )," J. Pengemb. Teknol. Inf. dan Ilmu Komput., vol. 3, no. 6, 2019.

[5] N. Fath and R. Ardiansyah, "Sistem Monitoring Alat Pemberi Pakan Ikan Otomatis Menggunakan NodeMCU Berbasis Internet of Things," Techno.Com, vol. 19, no. 4, pp. 449-458, 2020, doi: 10.33633/tc.v19i4.4051.

[6] C. Stergiou, K. E. Psannis, B. G. Kim, and B. Gupta, "Secure integration of IoT and Cloud Computing," Futur. Gener. Comput. Syst., vol. 78, pp. 964-975, 2018, doi: 10.1016/j.future.2016.11.031.

[7] A. Munir, P. Kansakar, and S. U. Khan, "IFCIoT: Integrated Fog Cloud IoT: A novel architectural paradigm for the future Internet of Things," IEEE Consum. Electron. Mag., vol. 6, no. 3, pp. 74-82, 2017, doi: 10.1109/MCE.2017.2684981.

[8] G. Neagu, S. Preda, A. Stanciu, and V. Florian, "A Cloud-IoT based sensing service for health monitoring," 2017 E-Health Bioeng. Conf. EHB 2017, pp. 53-56, 2017, doi: 10.1109/EHB.2017.7995359.

[9] M. K. Anwar and D. Firdaus, "IMPLEMENTATION OF FACE SIMILARITY USING TINY FACE DETECTOR,” Int. J. Inf. Syst. Comput. Sci., vol. 4, no. 1, pp. 22-28, 2020.

[10] P. Setialana, T. B. Adji, and I. Ardiyanto, "Perbandingan Performa Relational, DocumentOriented dan Graph Database Pada Struktur Data Directed Acyclic Graph,” J. Buana Inform., vol. 8, no. 2, pp. 77-86, 2017, doi: 10.24002/jbi.v8i2.1079.

[11] A. Budiman and Noviardi, "Informasi Penerapan Keamanan Penggunaan Data Pada Database Kepegawaian Menggunakan Teknik Transparent Data Encryption," SATINSains dan Teknol. Inf., vol. 2, no. 2, 2016.

[12] A. Kusyanti2, K. Amron, and F. Mohammad, "Pengamanan Data pada Media Penyimpanan Cloud Menggunakan Teknik Enkripsi dan Secret Sharing," J. Pengemb. Teknol. Inf. dan Ilmu Komput., vol. Vol. 2, No. 11,u, no. 11, pp. 4863-4869, 2018, [Online]. Available: http://j-ptiik.ub.ac.id.

[13] X. Chen, Z. Ji, Y. Fan, and Y. Zhan, "Restful API Architecture Based on Laravel Framework," J. Phys. Conf. Ser., vol. 910, no. 1, 2017, doi: 10.1088/17426596/910/1/012016.

[14] E. Susanti, "Implementasi RESTful API dalam Pembuatan Master Data Planogram Menggunakan Framework Flask (Studi Kasus: PT Sumber Alfaria Trijaya, Tbk)," Techno.Com, vol. 19, no. 3, pp. 295-307, 2020, doi: 10.33633/tc.v19i3.3468.

[15] A. S. Mustaqim, D. Kurnianto, and F. T. Syifa, "Implementasi Teknologi Internet of Things Pada Sistem Pemantauan Kebocoran Gas LPG dan Kebakaran Menggunakan Database Pada Google Firebase," Elektron J. Ilm., vol. 12, no. 1, pp. 34-40, 2020, doi: 10.30630/eji.12.1.161.

[16] D. M. Ibrahim, R. Primananda, and M. Data, "Perbandingan Performa Database Apache HBase dan Apache Cassandra Sebagai Media Penyimpanan Data Sensor Internet of Things," Pengemb. Teknol. Inf. dan Ilmu Komput., vol. 2, no. 8, pp. 2943-2949, 2018.

[17] E. Edy, F. Ferdiansyah, W. Pramusinto, and S. Waluyo, "Pengamanan Restful API menggunakan JWT untuk Aplikasi Sales Order," J. RESTI (Rekayasa Sist. dan Teknol. Informasi), vol. 3, no. 2, pp. 106-112, 2019, doi: 10.29207/resti.v3i2.860.

[18] M. F. A. Tansa Trisna Astono Putri, Mhd. Dominique Mendoza, "Bruteforce In The Hydra Process And Telnet Service Using The Naïve Bayes Method," J. Mantik, vol. 3, no. January, pp. 31-38, 2019.

[19] A. Subari, D. Y. Tadeus, H. Winarno, and T. Yuwono, "Rancang Bangun Sistem Administrasi Kerja Praktek Dan Tugas Akhir Berbasis Web Menggunakan Framework Codeigniter," Gema Teknol., vol. 19, no. 4, p. 1, 2018, doi: 10.14710/gt.v19i4.19147.

[20] Y. W. Luthfi Muhammad, Data Mahendra, "Perbandingan performa reverse proxy caching nginx dan varnish pada web server apache," Pengemb. Teknol. Inf. dan Ilmu 
Komput., vol. 2, no. 4, pp. 1457-1463, 2018.

[21] A. Y. Chandra, "Analisis Performansi Antara Apache \& Nginx Web Server Dalam Menangani Client Request," J. Sist. dan Inform., vol. 14, no. 1, pp. 48-56, 2019, doi: 10.30864/jsi.v14i1.248.

[22] B. W. PUTRA, A. SAPUTRA, M. R. SANJAYA, and D. KURNIAWAN, "Enabling Collaboration of CodeIgniter Framework and RESTful API for Utilize Web Mobile Interface Implemented on Final Project Management System," Adv. Intell. Syst. Res., vol. 172, 2020, doi: 10.2991/aisr.k.200424.080. 